\title{
Uterine Infection, CTCAE
}

National Cancer Institute

\section{Source}

National Cancer Institute. Uterine Infection, CT CAE. NCI Thesaurus. Code C143917.

A disorder characterized by an infectious process involving the endometrium. It may extend to the myometrium and parametrial tissues. 